\title{
MATERIAL MODELLING OF TENSILE STEEL COMPONENT UNDER IMPULSIVE LOADING
}

\author{
Ribeiro, J. ${ }^{1 *}$, Santiago, A. ${ }^{1}$, Rigueiro, C. ${ }^{2}$, \\ ${ }^{1}$ ISISE - Departamento de Engenharia Civil, Faculdade de Ciências e Tecnologia, Universidade de Coimbra, \\ Rua Luís Reis Santos. Polo II da Universidade. 3030-788 Coimbra, Portugal. \\ 2 ISISE - Instituto Politécnico de Castelo Branco, Escola Superior de Tecnologia, \\ Av. Pedro Álvares Cabral n. ${ }^{\circ} 12$ 6000-084 Castelo Branco, Portugal
}

\begin{abstract}
The "T-stub" model is used in Eurocode 3 - part 1.8 as part of the "component method" for the representation of steel connection's tension zone and is usually responsible for providing ductility to the connection. Looking forward to establish the "T-stub's" maximum displacement capacity, fracture simulation of steel elements is here explored following "element deletion" technique for a given level of ductile damage. Material softening and triaxial stress state dependency are assessed based on finite element analysis of common uniaxial tension tests. Numerical model describing the "T-stub" behaviour and displacement capacity are compared against experimental tests of statically loaded "T-stub" specimens with thicknesses of 10 and $15 \mathrm{~mm}$.

Based on the calibrated FE model for monotonic loading, the behaviour of this tensile component is evaluated for impulsive loading regimes. The material behaviour is improved to take into account the possible development of elevated strain rates based on results from Split-Hopkinson Bar tests, through the incorporation of the Johnson-Cook's elevated strain rate law for material strain-hardening description.
\end{abstract}

KEYWORDS: Material characterization, Numerical modelling, Elevated strain rate, Fracture, Ductile damage.

\section{INTRODUCTION}

For most engineering applications mild steel can be considered as continuous solid material, due to the fact that the composing crystals are usually much smaller than the smallest geometrical dimension of interest to be analysed [1]. This simplification, added with the yielding criteria used to perform structural design, allows engineers to use the uniaxial tension tests to characterize mild steel material behaviour.

However, when is required to establish the degradation and loss of load carrying capacity of structural elements (i.e. beyond the instability point), material discontinuities become relevant. In the field of Continuum Damage Mechanics these discontinuities in the material (a porous medium) are introduced as homogenized variables (a continuum medium) generally represented in a Representative Volume Element (RVE) by "damage" [2], [3]. From a physical point of view, damage is always related to irreversible strains and to strain dissipation either on the mesoscale, the scale of the RVE, or on the microscale (the scale of the discontinuities) [2]. In mild steel specimens without macroscale flaws or cracks, the void nucleation occurs with little difficulty, therefore the fracture properties are controlled by the growth and coalescence of those voids, resulting in failure [3].

Looking forward to an accurate finite element simulation in terms of stiffness, resistance and especially ductility of bolted steel connections, the implementation of a failure criterion based on continuum damage mechanics is explored in this paper. The material model used in the FE simulations takes into account the softening branch of the stress-strain relationship to establish the fracture of structural elements using the "element deletion" technique. This technique allows the removal of finite elements from the mesh as they achieve a determinate value of damage, thus providing insight of the fracture pattern.

Moreover, mild steel is known to have its flow stress affected by the loading speed [1]. The influence of elevated strain rates is evaluated and included in the material model to assess the behaviour of the T-stub subject to impulsive loads. This behaviour is one of the topics being investigated in scope of the project "ImpactFire" at the University of Coimbra, which is focused on the evaluation of bolted steel connections subject to impact loading, as rather brittle failure modes might be triggered under such loading regimes.

\footnotetext{
* Corresponding author. Tel.: +351 239797 218; fax: +351 239797123.

E-mail address: joao.ribeiro@uc.pt
} 


\section{MATERIAL CARACTERIZATION}

\section{$2.1 \quad$ Monotonic evaluation}

Mild steel is macroscopically assumed as an isotropic material. Its constitutive characterization, for most engineering applications, can be obtained through quasistatic tension tests, from which the elastic modulus $(E)$ and the elastic $\left(f_{y}\right)$ and ultimate strengths $\left(f_{u}\right)$ of steel are easily acquired.

Figure 1 presents the results from quasi-static uniaxial tension tests, conducted in accordance to the standard EN 10002-1 [4] on a Universal Tensile Machine. During these tests, the load has been applied by controlling the induced displacement to reasonably low speeds $(0.03 \mathrm{~mm} / \mathrm{s})$, to emulate the static response of the steel. Both mild steel coupon (solid blue line) grade S355 and quenched steel grade 8.8 (dashed red line) were conducted providing suitable material characterization for FEA described in this paper. The mild steel specimens have been collected from the same steel batch as the material used to prepare the tested Tstub specimens (see chapter $\$ 4$ ), while the steel grade 8.8 were picked from the same sales box of bolts M20. Three tests for each material were conducted; the mean results from the test campaign are presented in Table 1 and Figure 1. The solid blue curve denotes that mild steel is in nature a ductile material, with the capacity of absorbing great amount of energy before fracture; while the red dashed line which, despite its much higher elastic and ultimate strengths, exhibits rather low ductility capacity.

Concerning the stress-strain relationship for mild steel; it can be observed that the response exhibits firstly, a linear elastic development up to the yielding point where the elastic strength $\left(f_{y}\right)$ is defined; afterwards the response is inelastic, meaning that the deformation is no longer recoverable, and the relationship becomes nonlinear. This strain hardening phase is characterized by large deformations accompanied by the strength increase up to the ultimate tensile strength $\left(f_{u}\right)$. From this instability point on, the specimen will reduce its area due to the growth and coalescence of voids, visible through necking of the cross-section until fracture occurs. This phase of the stress-strain relationship is often referred to as the softening phase and its' modelling is addressed in chapter $\S 3$.

Table 1 - Material properties from uniaxial tension test

\begin{tabular}{c|c|cc|cc} 
& $\boldsymbol{E}$ & $\boldsymbol{f}_{\boldsymbol{y}}$ & $\boldsymbol{f}_{\boldsymbol{u}}$ & $\boldsymbol{\varepsilon}_{\boldsymbol{y}}$ & $\boldsymbol{\varepsilon}_{\boldsymbol{u}}$ \\
\hline & {$[\mathrm{GPa}]$} & {$[\mathrm{MPa}]$} & {$[\mathrm{MPa}]$} & {$[\%]$} & {$[\%]$} \\
\hline Steel S355 & 205.5 & 385 & 588 & 0.187 & 18.7 \\
\hline Bolt (8.8) & 213.5 & 721.3 & 1002 & 0.337 & 2.3
\end{tabular}

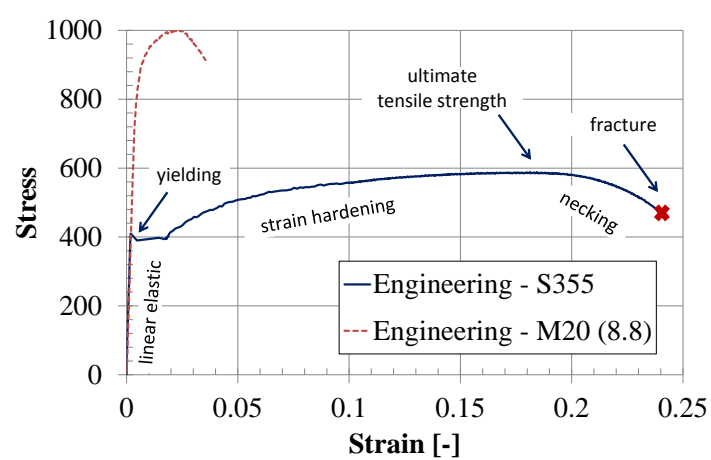

Figure 1 - Stress-strain relationship for S355 steel and bolt M20 (8.8)

\subsection{Strain rate evaluation}

Strain rate is the deformation, i.e. strain variation, that a material is subject per time unit, $d \varepsilon / d t$. Most ductile materials have strength properties which are dependent on the loading speed; mild steel is known to have its flow stress affected [1]. The effects of different strain rates on the stress-strain relationship of steel are illustrated in Figure 2 [5]. These true stress-logarithmic strain curves are obtained from an experimental programme carried out at the University of Coimbra, using a Compressive Split Hopkinson Pressure Bar (SHPB) for the dynamic tests [5] and the monotonic tests (previously discussed in chapter \$2.1). For the dynamic tests, an average strain rate around $\dot{\varepsilon}=600 \mathrm{~s}^{-1}$ is applied. Steel coupons have been also extracted from the tested T-stub specimen $(\mathrm{t}=10 \mathrm{~mm}, \mathrm{~S} 355)$ used for validation of the numerical model (see $\S 3$ ). Comparison against monotonic results showed that:

i. the yield and ultimate strengths $\left(f_{y}, f_{u}\right)$ increase near $50 \%$ the results obtained under monotonic loading;

ii. the total strain on rupture $\left(\varepsilon_{c u}\right)$ decreases, and;

iii. the elastic modulus $(E)$ remains indifferent to the loading rate.

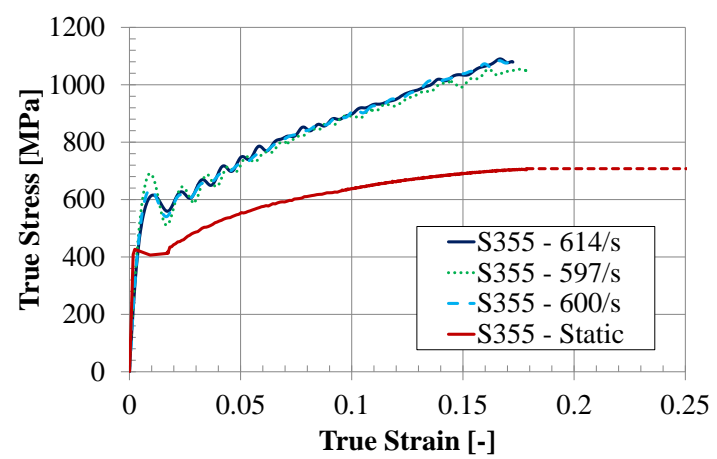

Figure 2 - True stress - logarithmic strain relationship of steel under high-strain rate (approx. $600 \mathrm{~s}^{-1}$ ) for $\mathrm{t}=15$ mm plate, S355 [5].

A simplified way to consider high strain rate enhancement in the stress-strain material law is to adopt a dynamic increase factor (DIF), given by the relation of 
the dynamic yield strength, $\sigma_{d y n}$ to the yield strength obtained under static conditions, $\sigma_{y}$ :

$$
D I F=\frac{\sigma_{d y n}}{\sigma_{y}}
$$

Finite element models aiming to simulate the behaviour of structural elements when subject to impact loads require a constitutive law representing the behaviour of materials for a range of strain rates. Amongst the most popular are the purely empirical Malvar model [6] and Cowper-Symonds model [7], that use logarithmic and power laws to relate the viscoplastic overstress to the strain rate. Johnson-Cook model [8] is also purely empirical, being able to account not only for the strain rate sensitivity but also for the thermal softening behavior. This constitutive law assumes that the slope of flow stress $\sigma_{y}$, is independently affected by each of the mentioned variables (equation 2):

$$
\sigma_{y}=\left[A+B \varepsilon^{n}\right] \cdot\left[\mathbf{1}+\boldsymbol{C} \boldsymbol{l n} \dot{\varepsilon}^{*}\right] \cdot\left[1-\left(T^{*}\right)^{m}\right]
$$

where: $A$ is the quasi-static yield strength; $B$ and $n$ represent the effects of strain hardening; $m$ is the thermal softening fraction; $T^{*}$ is a non-dimensional parameter defined based on the melting and transition temperatures to take account for material softening due to temperature variation; $\varepsilon$ is the equivalent plastic strain; $\dot{\varepsilon}$ is the strain rate; $\dot{\varepsilon}^{*}=\dot{\varepsilon} / \dot{\varepsilon}_{0}$ is the reference dimensionless plastic strain rate $\left(\dot{\varepsilon}_{0}=0.001 \mathrm{~s}^{-1}\right)$ and $C$ is the strain rate constant.

Thus, based on the results from SHBT [5] presented before and using the second term of Johnson-Cook's law (equation 2), $\mathrm{C}_{\text {steel }}=0.039$ for $600 \mathrm{~s}^{-1}$ is calculated to fit the experimental data [5] (Figure 2). The dependency on the strain rate of the bolts' material is accounted considering literature reports: impact tests on A 325 bolts recovered from the WTC debris showed very low sensitivity to strain rate [9], showing that high strength steels are less sensible to the effects of strain rate variation. According to Chang and his co-authors [10], a dynamic increase factor (DIF) of 1.1 may be considered for the bolts. This value has been adopted in the current study, thus a value of $\mathrm{C}_{\text {boll }}=0.0072$ is obtained. Nonetheless, the welds are assumed to have the same strain rate sensitivity as the base steel. Figure 4 provides the applied DIF for strain rate values between 0.001 and $600 s^{-1}$ following the Johnson-Cook law.

\section{FAILURE ASSESSMENT}

\subsection{Preliminary Damage Evaluation}

Most metal alloys exhibit one of four types of fracture: fatigue fracture, cleavage fracture, intergranular fracture or ductile fracture. For materials with a stress-strain relationship represented by an elasto-plastic with isotropic hardening evolution, as for example the mild steel under quasi-static loading in tension, failure is characterized by a ductile fracture mechanism [2]. The fracture is called ductile when it results from void nucleation followed by their growth and coalescence [3].

Figure 5 presents the characteristic stress-strain behaviour of a material undergoing damage; the dashed curve represents a generic material response without damage definition, while the solid line corresponds to the damaged stress-strain relationship. In this figure, $\sigma_{y 0}$ and $\bar{\varepsilon}_{0}^{p l}$ are the yield strength and equivalent plastic strain at the onset of damage, while $\bar{\varepsilon}_{f}^{p l}$ is the equivalent plastic strain at failure [11].

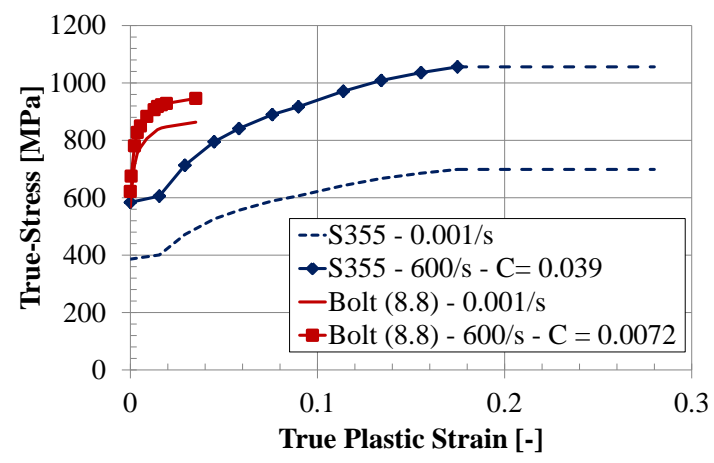

Figure 3 - Stress-strain relationship for mild steel and bolts considering strain rate sensitivity (see §4.2).

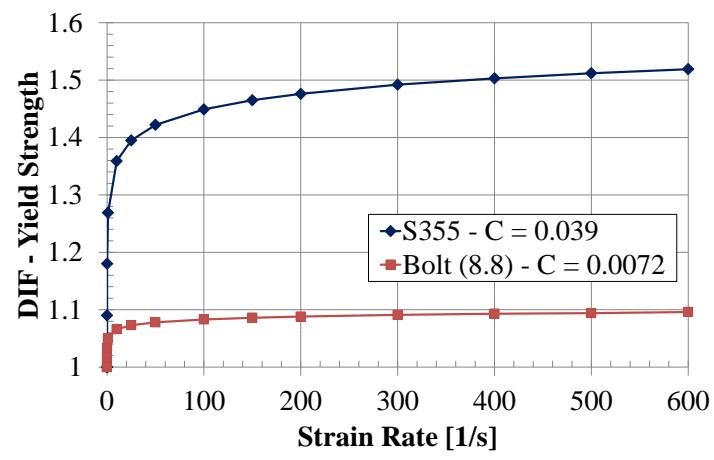

Figure 4 - Dynamic increase factor (DIF) of the yield strength as function of the strain rate.

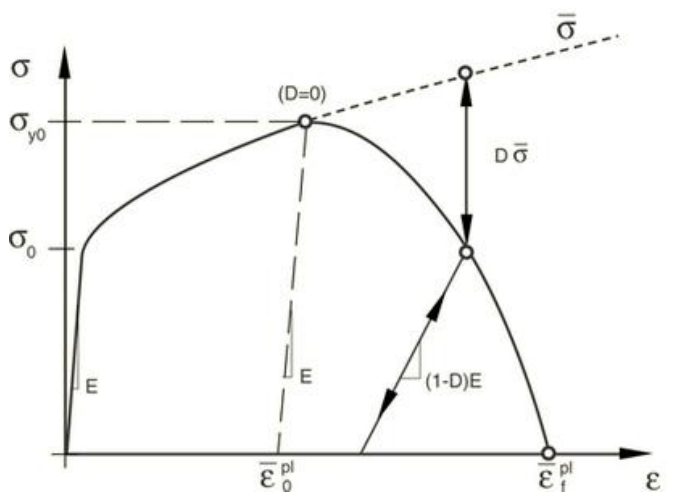

Figure 5 - Stress-strain curve with progressive damage degradation [11]. 
Amongst other failure models to predict the beginning of damage, the formulation proposed by Hooputra and co-authors [12] is included in the software ABAQUS package [11], used to perform the reported FE analyses. The model assumes that two main relevant mechanisms can induce fracture of a ductile metal: i) ductile fracture due to nucleation, growth, and coalescence voids; ii) shear fracture due to shear band localization. In this paper, only the model for ductile fracture is implemented; it assumes that the equivalent plastic strain at the beginning of damage, $\bar{\varepsilon}_{0}^{p l}$ is dependent on the strain rate and stress triaxiality, defined by $\left(\sigma_{\mathrm{H}} / \sigma_{\text {eq }}\right)$, where $\sigma_{\mathrm{H}}$ is the hydro static pressure stress and $\sigma_{e q}$ is the equivalent Von Mises stress. Additionally, a law establishing damage evolution is also required. Damage evolution description based on linear displacement requires the definition of the effective plastic displacement $\bar{u}^{p l}=L . \bar{\varepsilon}_{f}^{p l}$, where $\bar{\varepsilon}_{f}^{p l}$ is the equivalent plastic strain at failure and $L$ is the characteristic length of the finite element; due to strain localization in elements situated in the necking development zone, the progressive damage response is mesh dependent [11]. As elements reach a user defined level of degradation (for instance, the maximum degradation of $D=1)$ following $\sigma=(1-D) \cdot \bar{\sigma}$, elements may be either kept or removed from the mesh. Hooputra and co-authors [12] advise that the procedure is suitable to predict crack initiation zones, but that element removal should be regarded as preliminary assessment for crack propagation simulation.

\subsection{Failure modelling}

Implementation of the failure criterion discussed above is assessed on a simple uniaxial quasi-static tensile test with $t=10 \mathrm{~mm}$ thickness. The experimental strainstress material properties are obtained from the mechanical extensometer with an initial gauge length $L_{0}$ $=30 \mathrm{~mm}$ (Figure $6 \mathrm{~d}$ ). Measurement of the final gauge length after fracture is $L_{\mathrm{u}}=42 \mathrm{~mm}$, corresponding to a total extension after fracture equal to $40 \%$.

The geometry and FE mesh of the numerical model follows the dimensions of the tested coupon (Width $\mathrm{x}$ Thickness $=20 \times 10 \mathrm{~mm}^{2}$ ). The model is built with three-dimensional 8-node linear brick solid elements (C3D8R - also explained in \$4.1), and a static general analysis with displacement based loading is used. Symmetry conditions are taken into account, therefore only a quarter of the coupon is modelled. Typically a structured mesh technique is employed; the meshing constraints lead to an element size of $1.5 \times 1.5 \times 1.2 \mathrm{~mm}^{3}$ at mid height of the specimen (Figure $6 a$ and $b$ )). This numerical model is able to describe the material behaviour and to predict the failure experimentally observed (Figure $6 c$ and d). Figure $6 c$ ) shows depicts an increment within the softening phase with the damage scalar variable pattern (SDEG): elements with $D \geq 1.0$ have been deleted, while the deformed mesh clearly exhibits necking in the gauge length.

Figure 7 represents the procedure developed for modelling the material:

i. blue curve - the material curve obtained through the uniaxial quasi-static tensile test - Engineering S355 - T10 (see §2.1);

ii. green curve - strain-stress relationships obtained from the numerical model without progressive damage definition - Numeric - No Damage;

iii. red curve - strain-stress relationships obtained from the numerical model considering a strain at rupture of $18.7 \%$ (in accordance with Table 1). The damage evolution, as defined in $\S 4.1$, has been set to follow a linear law with an effective plastic displacement of $\overline{\mathrm{u}}^{\mathrm{pl}}=1.5 \mathrm{~mm}$. The numerical curve matches the experimental one very closely Numeric $-(10)-\mathrm{u}=1.5$.

This model allows the calibration of the equivalent plastic strain at the onset of damage, $\bar{\varepsilon}_{0}^{\mathrm{pl}}$ for the stress triaxiality ratio for pure tension of $\sigma_{\mathrm{H}} / \sigma_{\text {eq }}=1 / 3$. The equivalent plastic strain for other triaxial stress states have been extrapolated, following the formulation included in the ductile damage failure model by Lemaitre [2].

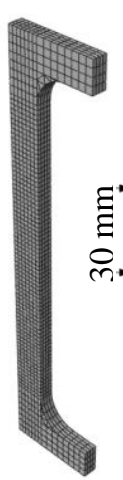

a)

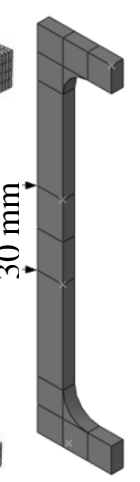

b)

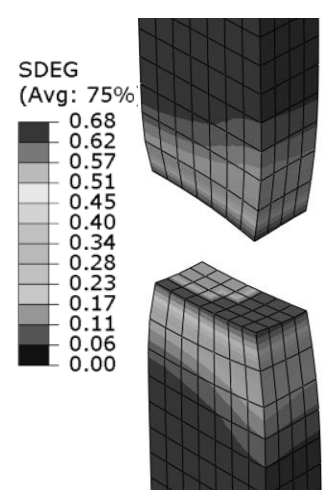

c)

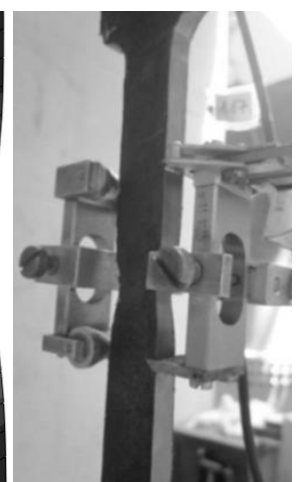

d)
Figure 6 -a) Finite element model representing 1/4 of the coupon test; b) gauge length; c) scalar damage pattern; d) uniaxial coupon test.

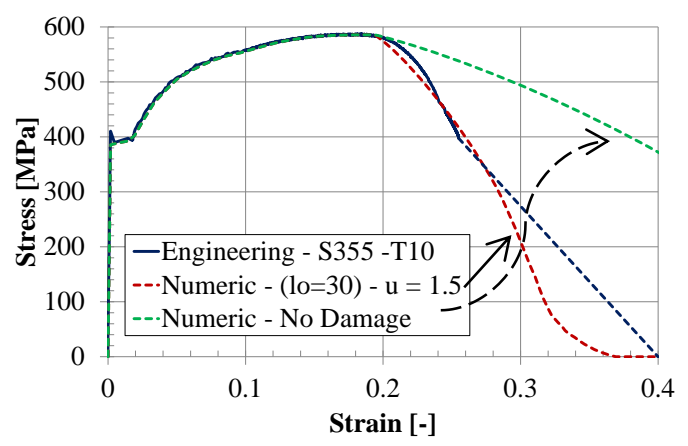

Figure 7 - Damage model assessment: Comparison of the stress-strain relationship obtained by experimental tests and numerical simulations. 


\section{APPLICATION: T-STUB MODEL}

\subsection{The T-stub model}

The T-stub model is chosen to exemplify the material modelling of tensile steel components (Figure 8). The T-stub model is used to describe the tension zone components of steel connections, namely the end-plate in bending, column flange in bending and the flange cleat in bending. The formulation to calculate its plastic resistance and initial stiffness are presented in chapters 6.2.4 and 6.3.2 of the Eurocode 3, Part 1.8 [13]. Concerning the rotational capacity, in chapter 6.4 of the same standard is referred that the previous components, additionally to the column's web in shear, are the components able to provide rotation capacity to a beamcolumn connection subject to bending. Nonetheless, guidance to predict its post-limit stiffness and displacement capacity is still absent as well as its resistance when considering rapidly applied dynamic loads.
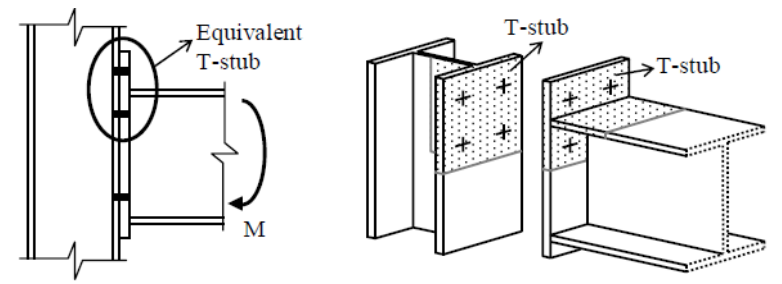

Figure 8 - "T-stub" section [14].

\subsection{Description of FE model}

The T-stub model analysed in this paper is drawn from a previous study carried out at the University of Coimbra, where experimental and numerical studies under monotonic static loading were developed [15], [16]. Figure 9 presents the dimensions of the test specimens and Figure 10 depicts the numerical model's boundary condition and mesh discretization. Two T-stubs were studied: thickness of the flange equal to 10 and $15 \mathrm{~mm}$; the steel grade is S355 and the bolts M20 grade 8.8 are fully threaded.

The FE analyses are conducted with the software ABAQUS [11] using its implicit/dynamic algorithm for quasi-static application, to solve the non-linear problem. The FE model is composed of four parts (Figure 10): (i) rigid back T-stub; (ii) tested T-stub; (iii) bolt, (head and shank as a single piece) and (iv) pull-out plate (web). Contact conditions are modelled between all the four parts namely: (i) the bottom flange surface with the back T-stub bottom flange; (ii) bolt shank with flanges bolt hole; (iii) top flange surfaces with bolt head; and (iv) pull out plate contact with the tested T-stub flange once the welds showed very little penetration. The welds are modelled in the tested T-stub part and connected to the pull out plate with a tie constraint property. Normal contact conditions are accomplished with "hard-contact" property allowing for separation after contact, and the tangential behaviour has been assumed with a friction coefficient of 0.2 following "penalty" formulation. Bolt modelling follows the nominal geometry (bolt shank diameter of $20 \mathrm{~mm}$ and the hole diameter $22 \mathrm{~mm}$ ). No pre-load is considered.

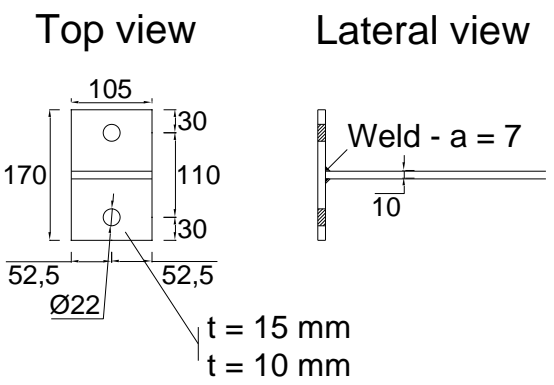

Figure $9-$ a) T-stub geometry.

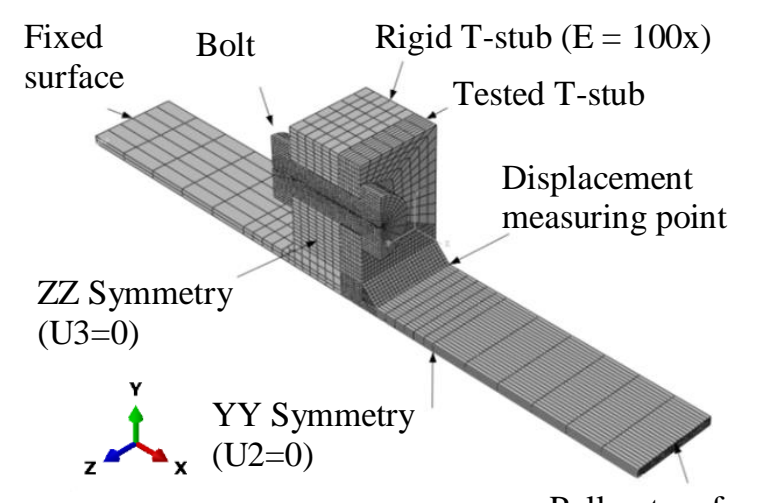

Figure 10 - T-stub model boundary conditions and mesh discretization.

The T-stub model has been simplified by the use of symmetry conditions in axes $y y$ and $z z$; therefore, displacements in these directions are restrained at the symmetry surfaces (Figure 10). The model is generated with solid element type C3D8R (first order reduced integration continuum element), allowing large deformations and non-linear geometrical and material behaviour. C3D8R is a valuable choice due to its reduced integration (only 1 integration point) allowing for reductions in calculation time, while it provides hour-glass behaviour control. Generally a structured mesh technique with "Hex" element shape is used, except for the weld zone where a "Wedge" element shape is employed.

Mesh sensitivity analyses were previously conducted assuring that a discretization of at least 4 elements through the thickness of bending-dominated plates (Tstub flanges), and a concentrical mesh around the bolt area with $8 \times 6$ (edge $\times$ diagonal) elements provided accurate results, whilst optimizing calculation time and reducing convergence problems. On the other hand, in zones where the strain gradients are negligible (near the end of the webs and the rigid back T-stub), coarser mesh discretization has been used. 


\subsection{Material properties}

Material nonlinearity is included by specifying a nonlinear stress-strain relationship for material hardening; Von Mises criterion is considered to establish the yield surfaces with the associated plastic flow for isotropic materials [11]. In order to consider large strains and large displacements, the monotonic stress-strain relationships obtained in the previously mentioned uniaxial coupon tests for the steel (Sections $\$ 2.1$ and §3) and for the M20 grade 8.8 bolt, have been employed in the true-stress - logarithmic plastic strain form - Eqs. (3), (4) and Figure 4.

$$
\begin{gathered}
\varepsilon_{\text {true }}=\ln \left(1+\varepsilon_{\text {eng }}\right) \\
\sigma_{\text {true }}=\sigma_{\text {eng }}\left(1+\varepsilon_{\text {eng }}\right)
\end{gathered}
$$

Once the bolt geometry follows nominal dimensions, bolt material properties have been updated to take into account the reduced tensile shank area. Material properties for the weld are assumed equal to the base steel plates. For the study of the effects of impulsive loads, DIFs reported in Section $\$ 2.2$ are employed.

Material behaviour includes the ductile failure modelling presented previously for both the steel (Section §3) and the bolt. For the latter, the equivalent plastic strain dependency to the triaxiality stress state is built considering a strain at rupture of $30 \%$. For the linear damage evolution description, a reduced effective plastic displacement of $\overline{\mathrm{u}}^{\mathrm{pl}}=0.1 \mathrm{~mm}$ is used due to the bolts' rather brittle behaviour. Despite the possible differentiate behaviour, damage properties remain the same when studying the behaviour of T-stubs subject to impulsive loads.

\subsection{T-stub - Validation to monotonic loading}

The validation of the numerical model for both T-stubs is based on experimental results [15]. Figure 11 compares the numerical (T-xx-DynQS) with the experimental response (T-xx-Test\#1 and Txx-Test\#2). It can be observed that the numerical models accurately predict the global behaviour of the T-stub component up to failure for both thicknesses. The triangular marker in Figure 11 identifies the last increment before damage is detected in the bolt, and it will be treated as a reference increment for the study of the strain patterns presented in Figure 12.

The analysis of the equivalent plastic strain patterns (PEEQ) in Figure 12a) shows the development of two plastic hinges per T-stub leg, for T-10, while for T-15 only the one next to the weld toe is completely developed; this is in accordance with the Eurocode 3, part 1.8, where the plastic failure modes are mode 1 and mode 2, respectively [15]. Figure 12b) compares the damage scalar variable (SDEG) for the reference time increment. Next to the weld toe, T-10 exhibits SDEG values around 4 times higher than the ones in $\mathrm{T}-15$; this is in agreement with experimental evidences, where cracks were detected prior to the bolt rupture in the heat affected zone on T-10-Test\#1 specimen (followed closely by the numerical response in Figure 11a) and not on the T-10-Test\#2 and T-15 specimens (Figure 12c). Figure 13 depicts an increment after the reference time increment, where the bolts are unable to hold the applied loading and some elements have already reached a level of damage of $\mathrm{D}=1$, and thus have been deleted from the mesh. Separation of the bolt in two different bodies is clear for both models; model $\mathrm{T}-15$ presents accurate prediction of the displacement capacity - Figure 11 . However, for T-10 specimen the initial cracks detected in the heat affected zone induced flange fracture before the bolt failure (Figure 12c). This difference may be attributed the material model adopted for the welded zone, which is the same as the one considered for the base material.
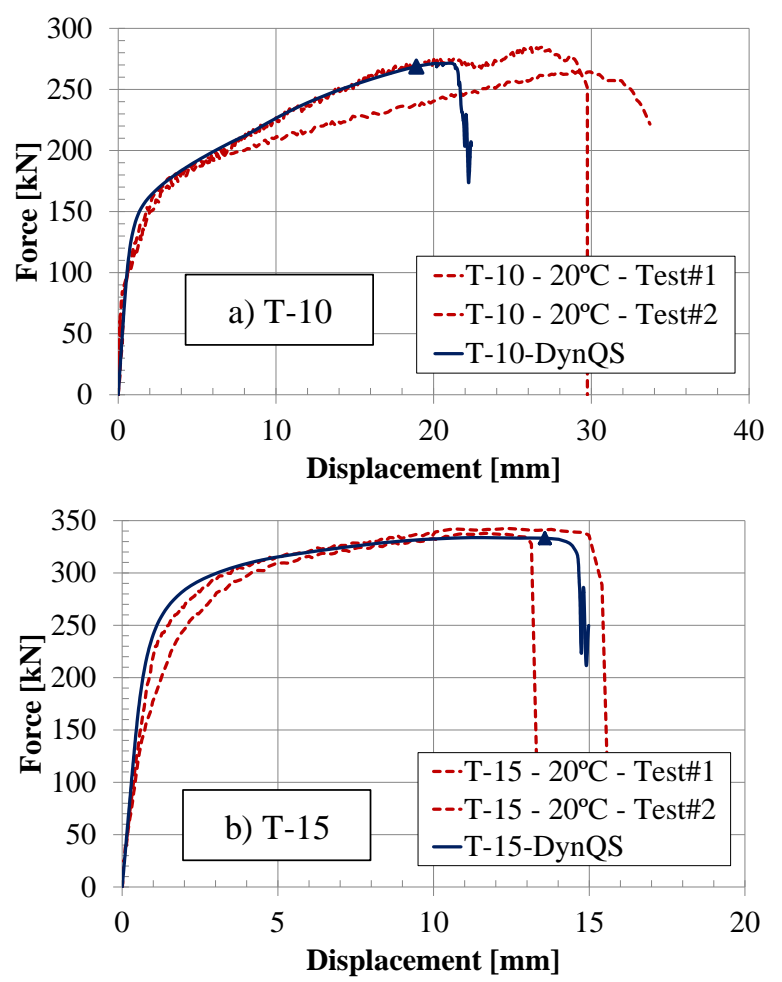

Figure 11 - Force displacement curve for monotonic loading: Numerical versus experimental results.

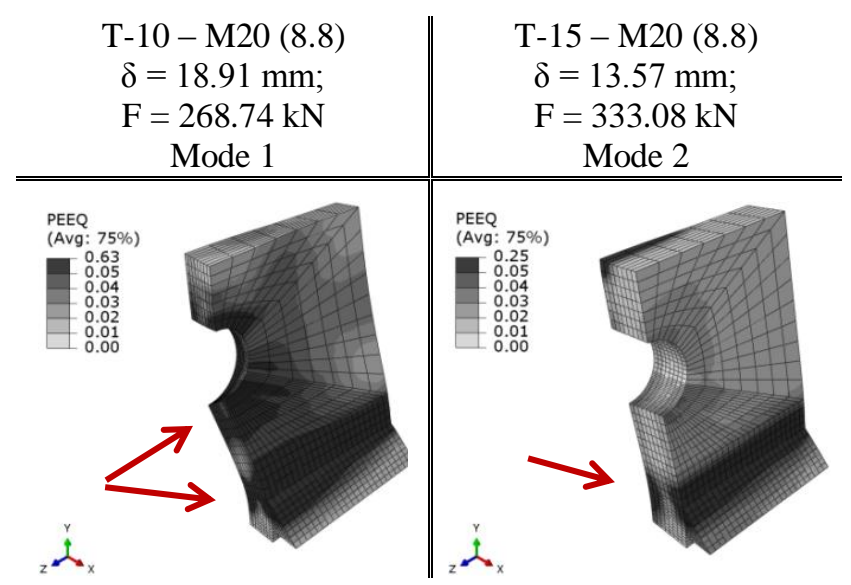




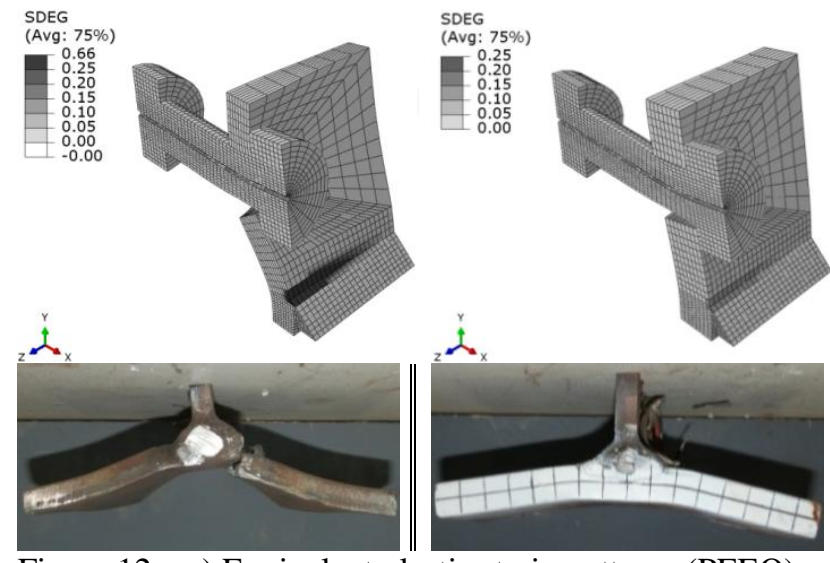

Figure 12 - a) Equivalent plastic strain patterns (PEEQ); b) Damage scalar variable (SDEG) [-] for the reference time increment identified in Figure 11 ; c) experimental failure modes [15].

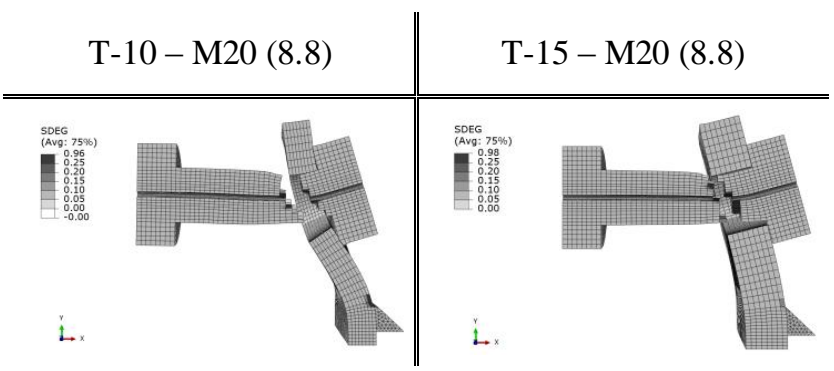

Figure 13 - Damage scalar on T-10 and T-15.

\subsection{T-stub - Behaviour to impulsive loading}

Studies assessing the effects of rapidly applied dynamic loads are made considering the maximum static resistance observed in monotonic, $\mathrm{P}=1 \times \mathrm{F}_{\max }$, and extended to evaluate peak loads of $\mathrm{P}=2 \times \mathrm{F}_{\max }$ and $\mathrm{P}=$ $4 \times F_{\max }$. Loads are set to rise to its peak in a very short time period of 20 milliseconds, remaining applied for the same time period.

Figure 14 compares the static and dynamic responses of both reference T-stubs: $\mathrm{T}-10$ and $\mathrm{T}-15$. The elastic stiffness is not affected, as the elastic modulus of steel remains unchanged for higher strain rates; while the effects of elevated strain rates can be observed through the increase in the plastic strength and in the stress flow. Short time application of the monotonic failure load value ( $\left.\mathrm{P}=1 \times \mathrm{F}_{\text {máx }}\right)$ has not lead to the failure of the $\mathrm{T}$ stubs, and even a decrease in the maximum displacement is observed. For other peak load levels, specific observations comparing monotonic and dynamic responses are reported:

i. An increase in the plastic resistance: $28 \%$ and $9 \%$ for $\mathrm{T}-10$ and $\mathrm{T}-15$, respectively, as noted by the markers in Figure 14, calculated in accordance with Jasparts's [17] method to establish the plastic resistance;

ii. Ultimate failure load is increased for both T-stubs (16\% and $18.6 \%$ increase for $\mathrm{T}-10$ and for $\mathrm{T}-15$, respectively). The ultimate failure mode remains as the bolt rupture, therefore dependant on the bolt resistance capacity, justifying why this increase is similar for both models;

iii. A decrease in the displacement capacity is observed, especially on T-10, due to the reduced development of the plastic hinge near the bolt, as noted by comparing Figure 12a) and Figure 15, before the rupture of the bolt occurs.

iv. However, for the higher levels of applied dynamic load $\left(\mathrm{P}=2 \times \mathrm{F}_{\max }\right.$. and $\mathrm{P}=4 \times \mathrm{F}_{\max }$.), no differences in the response are noted.
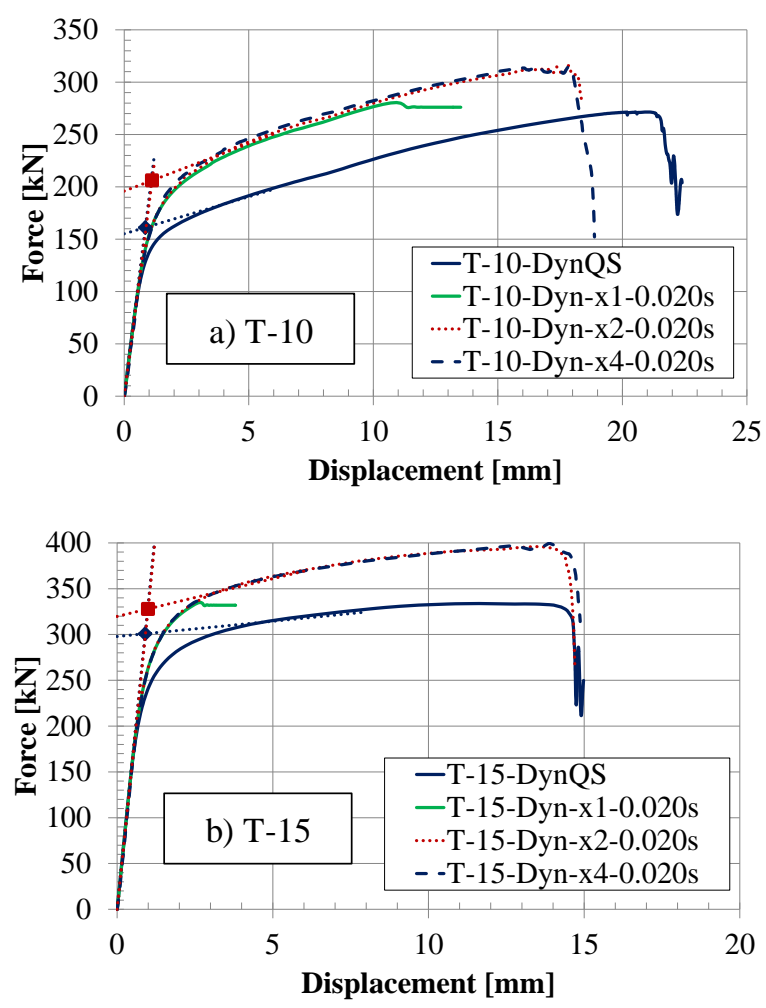

Figure 14 - Force versus displacement curves for a) T-10 and b) T-15 subject to static and dynamic loads.

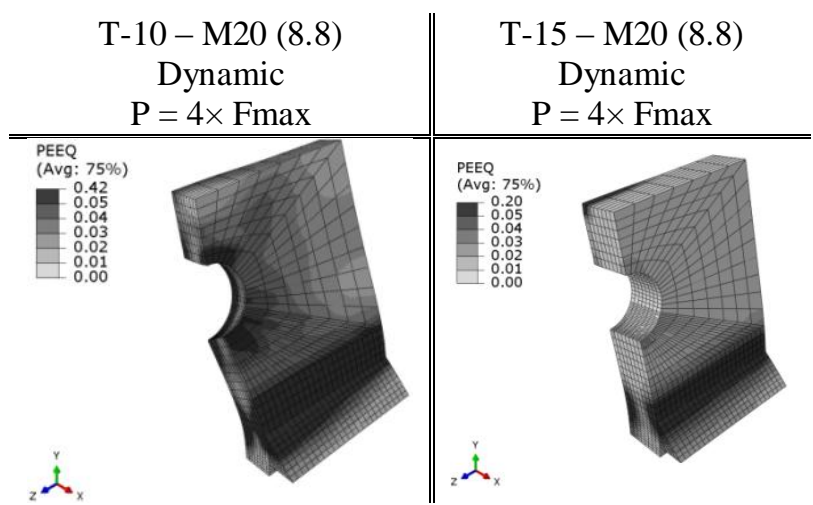

Figure 15 - Equivalent plastic strain patterns (PEEQ) for $\mathrm{T}-10$ and $\mathrm{T}-15$ for dynamic load $(\mathrm{P}=4 \times$ Fmax $)$. 


\section{CONCLUSIONS}

This paper presents material properties characterization and modelling for the analysis of the steel tensile component under impulsive loads. FE analyses presented replicate tests of welded T-stubs with thicknesses of 10 and $15 \mathrm{~mm}$ subject to monotonic load up to failure; the numerical model is found to be reliable within the elastic, the plastic transition and the postlimit phases, providing suitable prediction of the displacement capacity based on the ductile failure criterion implemented in the numerical model.

The model is improved to study the response when subject to rapidly applied dynamic loads. Elevated strain rate effects on mild steel are incorporated following the Johnson-Cook law based on results from Split Hopkinson bar tests undertaken on mild steel specimens, while a dynamic increase factor of 1.1 was assumed for the bolts. It was observed that in such loading regimes the force-displacement response:

i. is enhanced due to elevated strain rate effects, avoiding rupture when subject to a load equal the maximum static resistance when applied in a short time of $20 \mathrm{~ms}$;

ii. less ductile plastic failure modes are triggered leading to a reduction of the ultimate displacement capacity of the T-stub.

Experimental tests regarding the T-stub response subject to impact loads are currently on course at the University of Coimbra. Their results will provide validation of the formulated hypothesis and of the finite element models developed in this paper.

\section{ACKNOWLEDGEMENTS}

The authors acknowledge financial support from Ministério da Educação e da Ciência (Fundação para a Ciência e Tecnologia) under research project PTDC/ECM/110807/2009.

\section{REFERENCES}

[1] Dias da Silva, V., Mechanics and Strength of Materials, Springer-Verlag, 2006

[2] Lemaitre J. A course on damage mechanics. Berlin/Heidelberg: Springer-Verlag; 1992.

[3] Anderson TL. Fracture mechanics: fundamentals and applications. Boca Raton, FL: CRC Press; 1995.

[4] EN 10002-1, Metallic - Tensile testing Part 1: Method of test at ambient temperature, Brussels: European Committee for Standardization, 2001.
[5] Saraiva, E., "Variação das propriedades mecânicas do aço relacionadas com problemas de impacto em estruturas", Master Thesis at University of Coimbra, in portuguese, 2012.

[6] Malvar LJ, Crawford JE. Dynamic increase factors for steel reinforcing bars. In Twenty-eighth department of defence explosives safety board (DDESB) seminar. Orlando, Florida; 1998

[7] G. Cowper, P. Symonds, Strain hardening and strain-rate effects in the impact loading of cantilever beams, Tech. Rep., Brown University Division of Applied Mathematics, 1957.

[8] G.R. Johnson, W.H. Cook, "A constitutive model and data for metals subjected to large strains, high strain rates and high temperatures", Proceedings of the 7th International Symposium on Ballistics, The Hague, The Netherlands, pp. 541-547, 1983.

[9] Ellingwood, B.R., et al., Best Practices for Reducing the Potential for Progressive Collapse in Buildings 2007: NISTIR 7396, 2007.

[10]Chang, L., Hai, T. K., Ching, F. T., Tyas, A., "Numerical simulation of steel bolted beam-column connections subjected to dynamic loading", Applied Mechanics and Materials, Vol.82, pp. 314319, 2011.

[11] Abaqus Theory Manual \& Users Manuals, v.6.11, Hibbitt, Karlsson and Sorensen, Inc. USA, 2011.

[12] Hooputra, H., H. Gese, H. Dell, and H. Werner, A., "Comprehensive Failure Model for Crashworthiness Simulation of Aluminium Extrusions", International Journal of Crashworthiness, Vol. 9 (5), pp. 449-464, 2004.

[13]EN 1993-1-8, Eurocode 3: Design of steel structures Part 1.8: Design of joints, Brussels: European Committee for Standardization, 2005.

[14] Girão Coelho, A., Characterization of the ductility of bolted end plate beam-to-column steel connections, Ph.D. Thesis, Universidade de Coimbra, 2004.

[15]Barata, P., Santiago A., Rodrigues J.P., "Experimental behaviour of t-stub joint component at elevated temperatures, Vol I, pp. 345-354, in $2^{\circ}$ CISLACI 2013: Coimbra, Portugal, June 2013

[16] Ribeiro J., Rigueiro C., Santiago A., "Numerical behaviour of T-stub joint component at ambient and elevated temperatures", Vol. I, pp. $355-364$, in $2^{\circ}$ CISLACI 2013: Coimbra, 2013.

[17]Jaspart, J.P., Etude de la semi-rigidité des noeuds poutre-colonne et son influence sur la resistance des ossatures en acier (in French). PhD thesis, Department MSM, University of Liège, Belgium, 1991. 